\title{
Impact of the cell temperature on the energy efficiency of a single glass PV module: thermal modeling in steady-state and validation by experimental data
}

\author{
S. Jacques, A. Caldeira, Z. Ren, A. Schellmanns and N. Batut \\ GREMAN - UMR-CNRS 7347 \\ University of Tours \\ 7 avenue Marcel Dassault, 37200 Tours (France) \\ Phone number: +33 (0)2 473613 25, e-mail: sebastien.jacques@univ-tours.fr
}

\begin{abstract}
This paper deals with a simplified and meaningful thermal model used to extract the cell temperature of a photovoltaic (PV) module. This model that takes into account the ambient temperature, incident irradiance and wind velocity is calibrated using a complete experimental database. The results of the thermal modeling provide a heat transfer coefficient law that could be implemented into a PV simulation tool. Two key elements of this approach may be highlighted. The results enable to better calculate the solar energy production of a PV module and to predict the energy efficiency of a PV system.
\end{abstract}

\section{Key words}

Thermal modeling, PV module, Steady-state, Solar energy efficiency prediction, Experimental validation.

\section{Introduction}

The energy efficiency of a photovoltaic (PV) module depends mainly on the value of its operating cell temperature $\left(\mathrm{T}_{\text {cell }}\right)$. Regarding the monocrystalline silicon cell technology which is already the most popular, its energy efficiency, specified in the Standard Test Conditions (STC: cell temperature equal to $25^{\circ} \mathrm{C}$, $1,000 \mathrm{~W} . \mathrm{m}^{-2}$ irradiance intensity with defined solar spectrum) is typically decreased $0.4 \%$ for every $1{ }^{\circ} \mathrm{C}$ [1]. However, the energy production of a PV module is not only dependent on the total irradiance, but also on other weather conditions in a proportion that has yet to be determined. In particular, the influence of ambient temperature, relative humidity, wind direction and speed has to be studied [2]. The wind speed, which is often neglected because of a lack of specific data, may especially be suitable for large scale PV systems (higher than $100 \mathrm{kWp}$ ) in so far as the modules are exposed to convective heat transfer on both sides [3].

The challenge is here to develop a simplified and meaningful PV thermal model in steady-state that could be implemented into specific software to better predict the energy production of a solar panel and estimate the performances of a PV system.
Researchers at GREMAN, a research unit funded jointly by the University of Tours (France) and the French National Center for Scientific Research (CNRS), have recently proposed a one-dimensional thermal model to analyze the effect of the cell temperature on the energy efficiency of a single glass PV module in steady-state [4]. This model shows that the wind speed seems to have a significant impact on the energy production of a PV module. Indeed, the heat transfer coefficient may be defined as a function of total irradiance, ambient temperature and wind speed. This coefficient particularly follows a linear law instead of a constant value usually taken into consideration by PV software such as PVsyst.

The purpose of the study described in this article is to calibrate the existing model using a complete experimental database. The ultimate aim is to predict the energy efficiency of a PV system from the cell temperature calculation of the solar panel. An example of prediction of PV plant $(2.6 \mathrm{kWp})$ energy efficiency is described. The results are compared to commercial software ones to highlight the robustness of the modeling approach.

\section{Thermal model reminder}

\section{A. Single glass PV module modeling}

Single glass PV modules are now widely used, especially for large scale power plants, because of their good costperformances ratio. Monocrystalline or polycrystalline PV cells are wired up in series. As can be seen in Fig. 1, EVA (ethylene-vinyl-acetate) is the most often used material for the encapsulation of PV cells. The solar cells are sandwiched between an upper tempered and textured glass sheet and a backing plate which is generally composed of a white Tedlar ${ }^{\circledR}$ film.

A simplified approach is used to describe the thermal behavior of the PV module in steady-state. It means that the time to the cell temperature to reach the equilibrium is not taken into consideration. If this were to be the case, the model should be composed of thermal resistance and capacitance network to provide the time constant under 
varying atmospheric conditions and particularly, a change of solar radiation [5].

As can be reminded in Fig. 1, the thermal model of a single glass PV module is assumed to be symmetrical to the encapsulated cells [4]. Heating is performed by thermal conduction. So, each layer of the solar panel is described as a conductive thermal resistance $\left(R_{\lambda}\right)$ that could be calculated from the physical properties of the materials. The front side and backside of the module are subjected to air-flow. The convective part is modeled with a thermal resistance $\left(\mathrm{R}_{\mathrm{h}}\right)$ that particularly depends on the heat transfer coefficient (h). Finally, the cell temperature $\left(\mathrm{T}_{\text {cell }}\right)$ may be defined in relation to the ambient temperature $\left(\mathrm{T}_{\mathrm{a}}\right), \mathrm{R}_{\lambda}$ and $\mathrm{R}_{\mathrm{h}}$-parameters, module area $(\mathrm{S})$ and heat flow $(\Phi)$, as in (1).

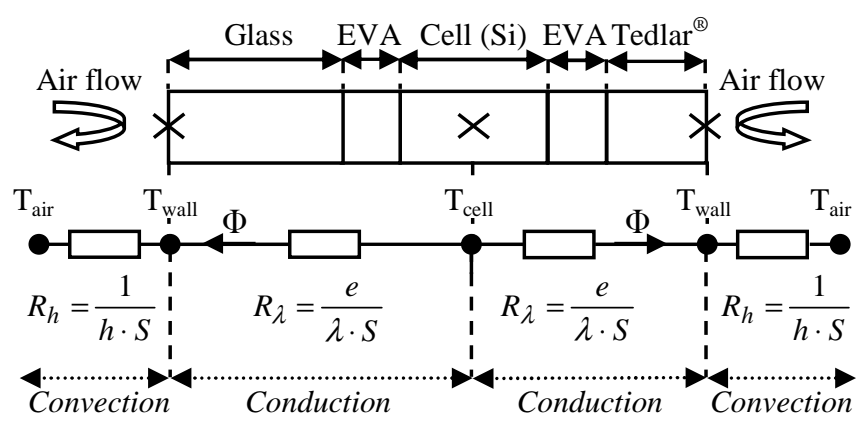

Fig. 1. Simplified one-dimensional thermal modeling of a single glass PV module.

$$
T_{\text {cell }}=T_{a}+\left(\mathrm{R}_{\lambda}+\frac{1}{h \cdot S}\right) \times \Phi
$$

\section{B. Cell temperature calculation using the NOCT approach}

The cell temperature is calculated using the ambient temperature and NOCT (Nominal Operating Cell Temperature) parameter which is particularly well-used by manufacturers to distinguish the performance of one

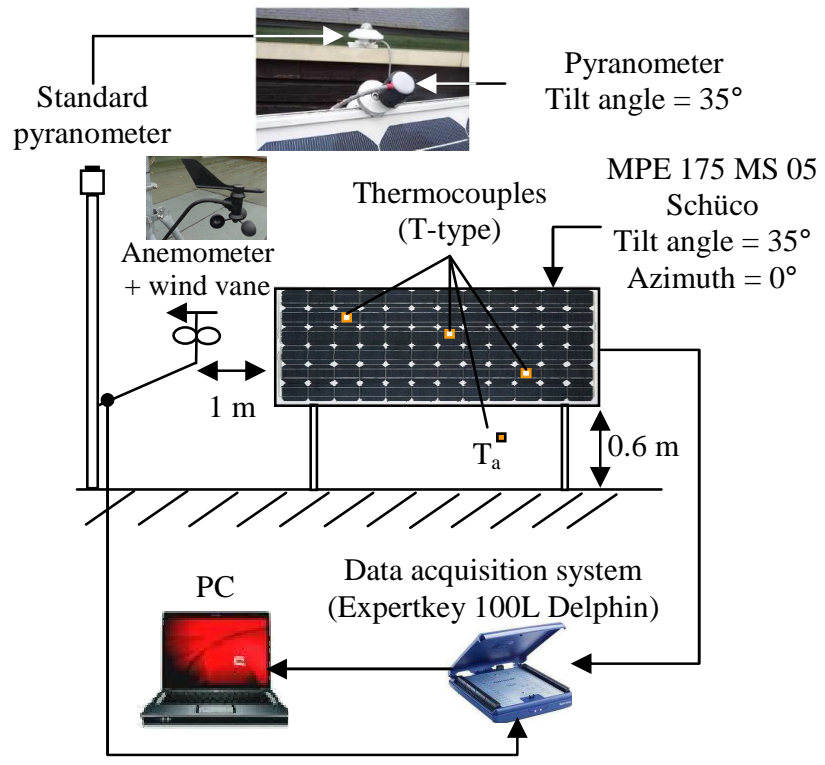

PV module design from another [6]. The NOCT value is determined under the Standard Operating Conditions. These conditions, which are based on the STC ones, give the following information: tilt angle of the PV module is equal to $45^{\circ}$, incident solar radiation $\left(\mathrm{G}_{\text {inc }}\right)$ of $800 \mathrm{~W} \cdot \mathrm{m}^{-2}$ (the STC document specifies $1000 \mathrm{~W} . \mathrm{m}^{-2}$ irradiance value) and ambient temperature $\left(\mathrm{T}_{\mathrm{a}}\right)$ of $20^{\circ} \mathrm{C}$, horizontal wind speed of $1 \mathrm{~m} . \mathrm{s}^{-1}$ on the front and back surfaces of the solar panel [7], [8].

A heat balance in open-circuit conditions can be written for both NOCT and operating conditions, as in (2). Even if this approach is used to calibrate the global heat balance using an experimental result that could be found in the module datasheet, this equation does not take into consideration various wind speed values. The impact of wind velocity (w) can easily be described from (1) and (2), as in (3), where the $\mathrm{h}_{\mathrm{NOCT}}$-parameter is the value of the heat transfer coefficient under the NOCT conditions. It is important to notice that this parameter is experimentally extracted from the $\mathrm{h}(\mathrm{w})$ relationship and compared with what could be found in literature.

$$
\begin{array}{r}
T_{\text {cell }}=T_{a}+(N O C T-20) \cdot \frac{G_{\text {inc }}}{800} \\
T_{\text {cell }}=T_{a}+(N O C T-20) \cdot \frac{G_{\text {inc }}}{800} \cdot \frac{R_{\lambda} S+\frac{1}{h(w)}}{R_{\lambda} S+\frac{1}{h_{N O C T}}}
\end{array}
$$

\section{Model calibration using experimental data}

\section{A. Experimental environment}

Fig. 2 shows the experimental environment.

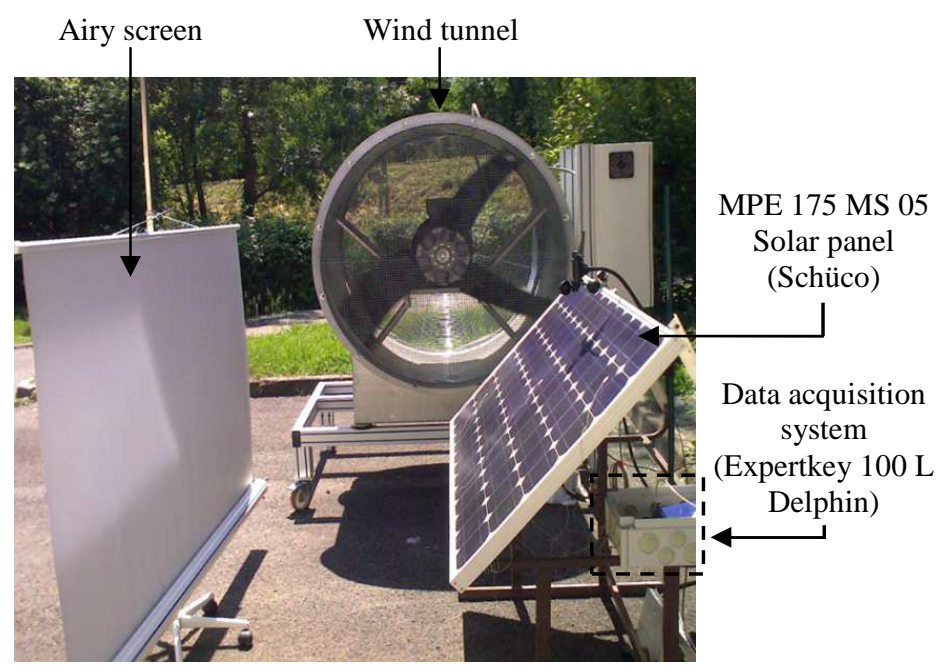

Fig. 2. Experimental environment. 
A 175 Wp monocrystalline solar panel (Schüco MPE 175 MS 05) was used for the measurements. A data acquisition system (Delphin Expert key 100L) is connected to a PC by Ethernet. Several reference temperatures are monitored and stored using the ProfiSignal software. T-type thermocouples were used: six were fixed on the front side and backside of the PV module, two thermocouples were directly in contact with the silicon to measure the cell temperature and two thermocouples were used to measure the ambient temperature. A pyranometer (tilt angle equal to $35^{\circ}$ ), directly mounted on the solar panel, was used to measure the global solar power incident on the module surface. This pyranometer was previously calibrated with a standard pyranometer where the measurement is specified by the manufacturer $\left(7 \mu \mathrm{V} \cdot \mathrm{kW}^{-1} \cdot \mathrm{m}^{-2}\right)$. The relative wind speed is measured using an anemometer (rotary magnet) which is fitted with a wind vane to check the wind direction. A reed switch is arranged in the plane of the magnet. It emits an electrical impulse every time the magnet passes over. The wind vane signals (frequency and voltage that is proportional to the rotation angle) are analyzed by the data acquisition system. A wind tunnel was used to set up the wind speed (the maximum speed value was equal to $40 \mathrm{~km} \cdot \mathrm{h}^{-1}$ ). An airy screen was set up to protect the PV module against moderate breezes. It is important to notice that all the outside experimental tests were done in sunny weather with a particular focus on the ambient temperature which had to be as stable as possible not to perturb the data acquisition.

\section{B. Heat transfer coefficient determination}

Several sets of measurements were done for a few weeks thanks to favorable weather conditions (incident radiation of $800 \mathrm{~W} . \mathrm{m}^{-2}$, ambient temperature that could be higher than $20{ }^{\circ} \mathrm{C}$, negligible breezes). The wind tunnel speed was adjusted from a $1 \mathrm{~km} \cdot \mathrm{h}^{-1}$ to $30 \mathrm{~km} \cdot \mathrm{h}^{-1}$. Fig. 3 shows that the h-parameter increases linearly with the wind speed. In particular, the value of the $\mathrm{h}_{\mathrm{NOCT}}$-parameter at $3.6 \mathrm{~km} \cdot \mathrm{h}^{-1}$, as specified in the Standard Operating Conditions, is about $16,7 \mathrm{~W} \cdot \mathrm{m}^{-2} \cdot \mathrm{K}^{-1}$. This value is closed to what can be found in literature i.e. between $15 \mathrm{~W} \cdot \mathrm{m}^{-2} \cdot \mathrm{K}^{-1}$ and $20 \mathrm{~W} \cdot \mathrm{m}^{-2} \cdot \mathrm{K}^{-1}$ [3], [5].

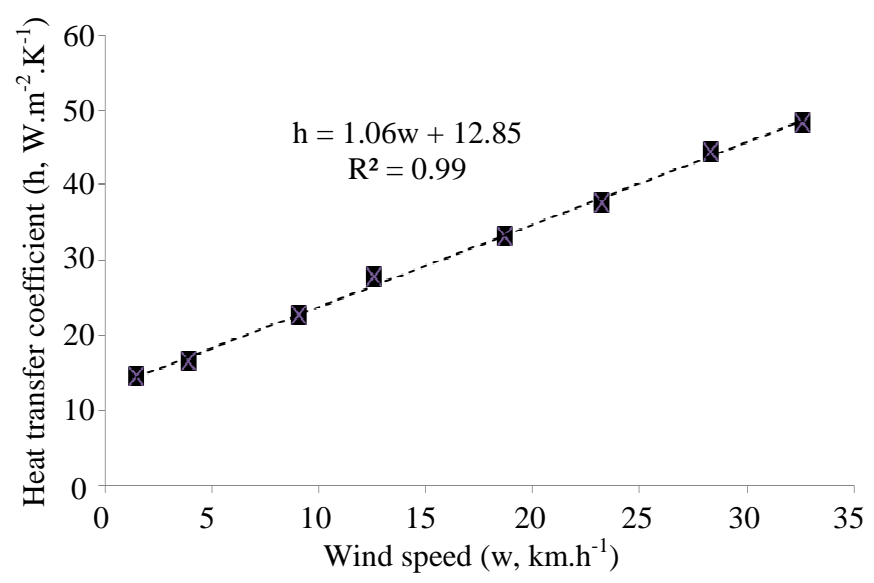

Fig. 3. Heat transfer coefficient evolution in relation to wind speed.

\section{Solar energy estimation of a PV plant}

\section{A. Implementation of the model in a new simulation tool}

The results of the thermal modeling (h-parameter in relation to wind speed) are directly implemented in a new PV simulator called "PVLab".

PVLab is a mathematical tool designed with MATLAB by GREMAN's researchers. It is strongly based on PVsyst which is currently the most widely used in Europe to study PV systems. PVsyst provides results in the form of a full report, specific graphs and tables, as well as data export for use in other software. PVLab retains the two main functions of PVsyst in terms of solar energy calculation of a PV module. The electrical modeling (see Fig. 4) is described as a single-diode equivalent circuit model including the effect of serial and shunt resistances [9], [10].

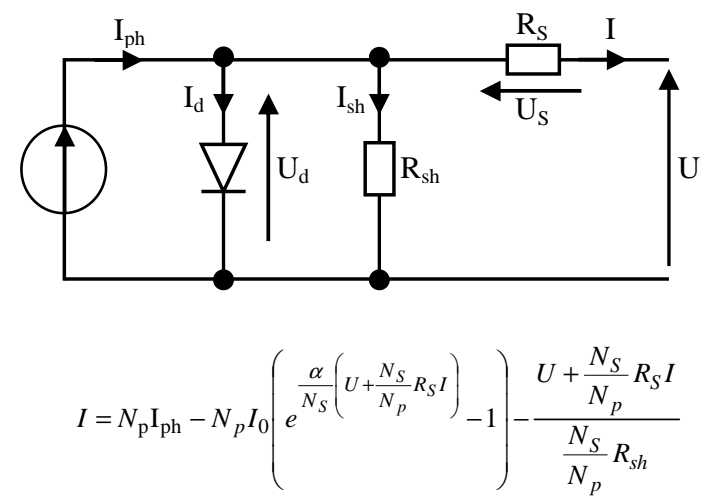

Fig. 4. Single-diode equivalent circuit modeling of a PV module.

Regarding the thermal part, it is important to remind that PVsyst uses the global heat balance approach. It means that the cell temperature is calculated from a complete global energy balance on the PV module depending on the ambient temperature $\left(T_{a}\right)$, incident irradiance $\left(G_{i n c}\right)$ and energy efficiency of the solar panel $(\eta)$, as in (4). Two constant values are particularly used: the optical absorption coefficient $(\alpha=0.9)$ and the heat transfer coefficient $\left(\mathrm{H}=29 \mathrm{~W} \cdot \mathrm{m}^{-2} \cdot \mathrm{K}^{-1}\right)$ to describe the impact of wind speed [1]. In this formula, the $\mathrm{G}_{\text {inc }}$-parameter is only related to one face of the PV module whereas the $\mathrm{H}$ parameter is related to both front and back faces.

$$
T_{\text {cell }}=T_{a}+\frac{\alpha \cdot \mathrm{G}_{\mathrm{inc}} \cdot(1-\eta)}{\mathrm{H}}
$$

The thermal part of mathematical model proposed in the PVLab tool is based on the results of thermal modeling of the solar panel as described previously. As a result, the cell temperature calculation is based on the NOCT approach, as in (3), taking into consideration the experimental results and particularly, the heat transfer evolution in relation to wind speed (see Fig. 3). 


\section{B. Case study: solar energy production calculation of a $P V$ module}

The results of the thermal modeling (h-parameter in relation to wind speed) are directly implemented in the new PVLab simulator. An example of a $2.64 \mathrm{kWp}$ solar power located at Tours in France $\left(47^{\circ} 23^{\prime} 38^{\prime \prime} \mathrm{N}, 0^{\circ} 41^{\prime} 48^{\prime \prime}\right.$ $\mathrm{E}, 35^{\circ}$ tilt angle value of the PV modules) plant was simulated with the PVLab system.

Firstly, the wind speed was equal to a constant value (i.e. $1 \mathrm{~m} . \mathrm{s}^{-1}$ ) as described in the SOC document. It is interesting to compare the results with the PVsyst ones. The data show that the two simulation tools give approximately the same annual solar energy production value $(2941 \mathrm{kWh}$ from PVLab results and $2930 \mathrm{kWh}$ from PVsyst ones).

Secondly, the impact of the wind speed through the hparameter was taken into consideration by the PVLab simulator. The annual solar energy production was calculated and compared with the results from the PVsyst simulator results (with a constant wind speed value, i.e. $\left.1 \mathrm{~m} . \mathrm{s}^{-1}\right)$. Fig. 4 shows the higher the wind speed value is, the higher the ratio between PVLab and PVsyst annual solar energy production calculation result is. For instance, the annual solar energy production is about 4.2\% higher than the one calculated with the PVsyst commercial tool at wind speed of $36 \mathrm{~km} \cdot \mathrm{h}^{-1}$.

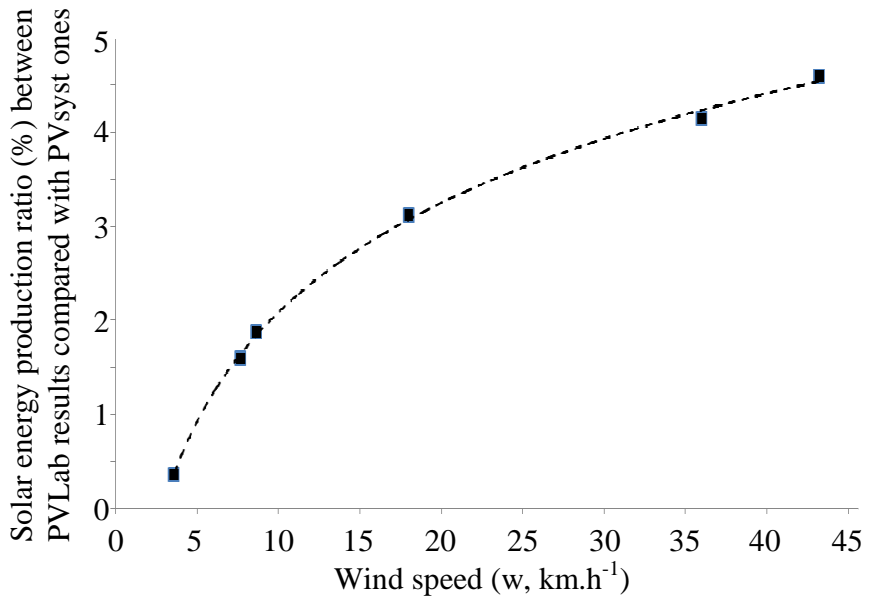

Fig. 4. Wind speed impact on the solar energy production of a $2.64 \mathrm{kWp}$ power plant: comparison between PVLab and PVsyst.

\section{Conclusion}

In this paper, a simplified and meaningful thermal modeling of a single glass PV module is proposed. This model helps to calculate the cell temperature from the irradiance, ambient temperature and wind speed. A complete experimental database enables to calibrate the model. Regarding the impact of wind speed, the results show that the heat transfer coefficient follows a linear law instead of a constant value generally taken into consideration in PV simulators such as PVsyst.

All these parameters are implemented in a new in-house simulation tool. The primary advantage of this mathematical modeling is that it provides a better solution to estimate the solar energy production of a PV module and thus, the energy efficiency of a PV plant. An example of calculation is given for a $2.6 \mathrm{kWp}$ PV plant. The results clearly show that the wind speed is of special significance in the calculation of the energy efficiency. The wind speed may have a greater impact for large scale power plants.

Many prospects could be highlighted from this study. The database has to be completed particularly for low irradiance values. The impact of wind direction has to be quantified through additional experimental measurements. Finally, it could be interesting to take into consideration transient phenomena to reinforce the energy efficiency estimation. However, it could be necessary to complete the thermal modeling of the PV module by taking into consideration thermal resistances and thermal capacitances.

\section{References}

[1] W. Marańda, M. Piotrowicz, "Extraction of thermal model parameters for field-installed photovoltaic module", in Proceedings of Microelectronics conference (MIEL 2010), 2010, pp. 153-156.

[2] G. M. Tina, S. Scrofani, "Electrical and thermal model for PV module temperature evaluation", in Proceedings of IEEE Mediterranean electrotechnical conference (MELECON 2008), 2008, pp. 585-590.

[3] PVsyst User's Guide, "Thermal Model," University of Geneva, 2010, pp. 41-42.

[4] F. Romary, A. Caldeira, S. Jacques, A. Schellmanns, "Thermal Modelling to Analyze the Effect of Cell Temperature on PV Modules Energy Efficiency", in Proceedings of European conference on power electronics and applications (EPE 2011), 2011.

[5] S. Armstrong, W.G. Hurley, "A thermal model for photovoltaic panels under varying atmospheric conditions", Applied Thermal Engineering 30 (2010), pp. 1488-1495.

[6] M. Muller, B. Marion, J. Rodriguez, "Evaluating the IEC 61215 Ed.3 NMOT procedure against the existing NOCT procedure with PV modules in a side-by-side configuration", in Proceedings of Photovoltaic specialists conference (PVSC 2012), 2012, pp. 697-702.

[7] K. Lynn, "Test method for photovoltaic module ratings", Florida Solar Energy Center (2001), pp. 697-702.

[8] R. Bharti, J. Kuitche, M.G. TamizhMani, "Nominal Operating Cell Temperature (NOCT): Effects of module size, loading and solar spectrum", in Proceedings of Photovoltaic specialists conference (PVSC 2009), 2009, pp. 1657-1662.

[9] E.M.G. Rodrigues, R. Melício, V.M.F. Mendes and J.P.S. Catalão, "Simulation of a Solar Cell considering Single-Diode Equivalent Circuit Model", Renewable Energy \& Power Quality Journal 9 (2011).

[10] S. Guo, T. M. Walsh, A.G. Aberle, M. Peters, "Analysing partial shading of PV modules by circuit modelling", in Proceedings of Photovoltaic specialists conference (PVSC 2012), 2012, pp. 2957-2960. 